\title{
Papillary Thyroid Carcinoma Spreading into Branchial Cleft Cyst
}

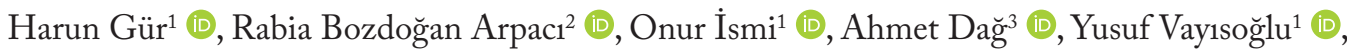 \\ Kemal Görür ${ }^{1}$ (D) \\ ${ }^{1}$ Department of Otorhinolaryngology, Mersin University School of Medicine, Mersin, Turkey \\ Case Report $>{ }^{2}$ Department of Pathology, Mersin University School of Medicine, Mersin, Turkey \\ ${ }^{3}$ Department of General Surgery, Mersin University School of Medicine, Mersin, Turkey
}

Abstract

ORCID IDs of the authors:

H.G. 0000-0001-6165-2350;

R.B.A. $0000-0002-1541-5108$

0.I. 0000-0001-5061-8907;

A.D. 0000-0002-1000-1379;

Y.V. 0000-0002-7132-1317;

K.G. 0000-0002-2147-4673.

Cite this article as: Gür H, Bozdoğan Arpacı R, İsmi O, Dağ A, Vayısıoğlu Y, Görür K. Papillary Thyroid Carcinoma Spreading

into Branchial Cleft Cyst. Turk Arch

Otorhinolaryngol 2019; 57(2): 95-8.

Corresponding Author:

Harun Gür; hrngur@hotmail.com

Received Date: 02.02 .2019

Accepted Date: 28.04.2019

Available Online Date: 26.06 .2019

D0l:10.5152/tao.2019.4151

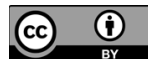

Content of this journal is licensed under a Creative Commons Attribution 4.0 International License.

Available online at www.turkarchotolaryngol.net
Papillary thyroid carcinoma (PTC) is the most common type of thyroid malignancy and it can cause cystic metastasis to the neck region. Branchial cleft cysts (BCCs) are among the most commonly encountered congenital cystic neck masses. PTC metastasis into $\mathrm{BCC}$ has been rarely reported in the literature. In this case report we report a patient presenting with a cystic neck mass for which fine needle aspiration biopsy was reported as benign cytology and eventually was diagnosed as PTC metastasis to the BCC. The importance of investigating the thyroglobulin levels in fine needle aspiration materials of cystic neck masses for early diagnosis of possible PTC metastasis is specifically emphasized.

Keywords: Branchial cleft cyst, papillary thyroid carcinoma, cystic metastasis, congenital, neck neoplasms

\section{Introduction}

Papillary thyroid carcinoma (PTC) is the most common histological type among thyroid cancers and represents $60-70 \%$ of all thyroid cancers. Typically, it is seen in the third and fourth decades of life and twice more in women than men. Occult carcinomas, in general, are smaller than 1.5 $\mathrm{cm}$, non-palpable, and mostly incidentally identified. Most of the patients present with a painless, slow-growing mass. This type of cancers tend to spread to the paratracheal and cervical lymphatics (1).

Branchial cleft anomalies are the most common congenital lesions of the neck after thyroglossal duct cysts. Second branchial cleft cysts (BCC) most commonly localize to the anterior of the sternocleidomastoid muscle (SCM). Malignancies rarely occur under the epithelial covering of the cyst (2).

Branchial cleft cysts rarely occur together with PTC. Reports of PTC metastasizing to the accompanying $\mathrm{BCC}$ and reaching a diagnosis of PTC after BCC excision are rare in the literature
(3). In this case report we present, in the light of the current literature, a BCC case that was reported as benign by fine needle aspiration biopsy (FNAB) but seen to contain PTC metastasis after excision.

\section{Case Presentation}

A 35-year-old male patient presented to our clinic with a painless mass on the left side of his neck that had been increasingly growing for nine months. The patient had no known comorbidity nor a history of smoking and alcohol consumption. In physical examination a mobile, soft and smooth-surfaced, painless mass of $4 \mathrm{~cm}$ was observed to the left of the neck in the $3^{\text {rd }}$ and $4^{\text {th }}$ levels. Computed tomography (CT) of the neck revealed a $3.5 \times 1.5 \mathrm{~cm}$ hypodense cystic lesion in the $3^{\text {rd }}$ and $4^{\text {th }}$ levels on the left side (Figure 1). After FNAB reported a benign cytology and cystic content, neck exploration was performed under general anesthesia with a preliminary diagnosis of BCC and the cystic mass medial to the SCM was excised (Figure 2, 3). Histopathologic examination of the cystic mass identified BCC with connective tissue and lymphoid aggregates on its wall, and 


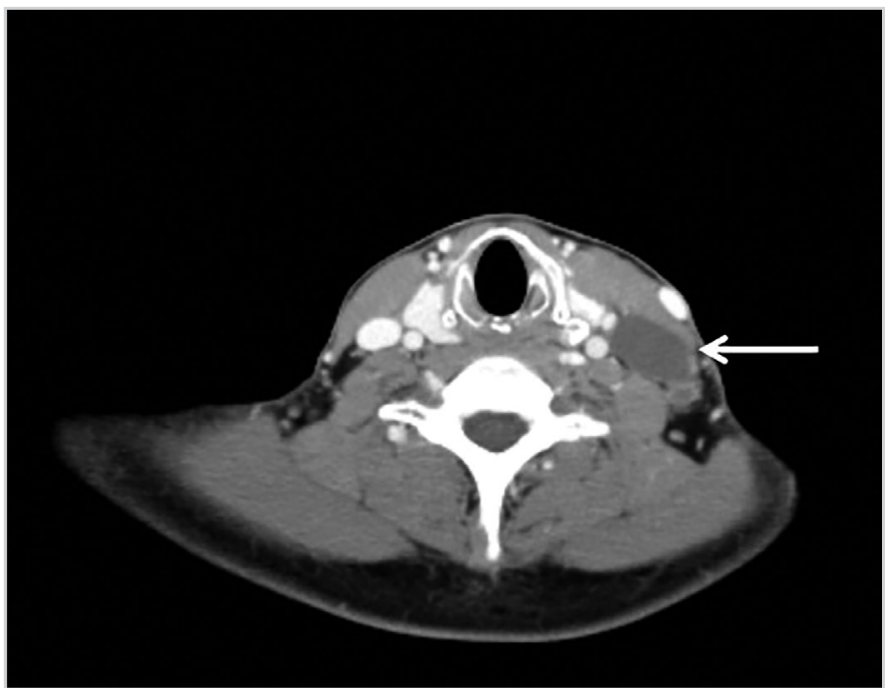

Figure 1. Computed tomography view of mass (arrow: cystic mass)

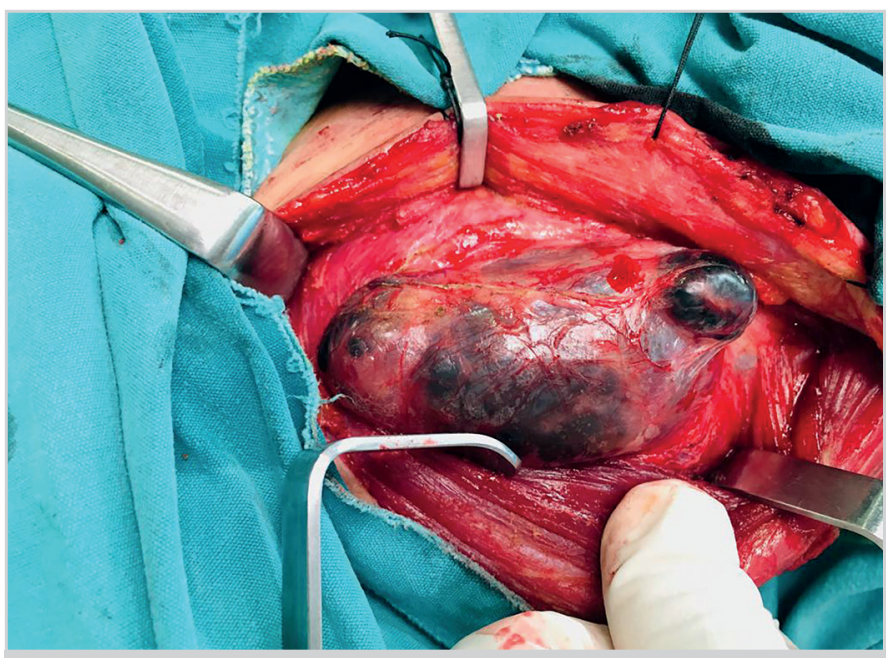

Figure 2. View of cystic mass during neck exploration

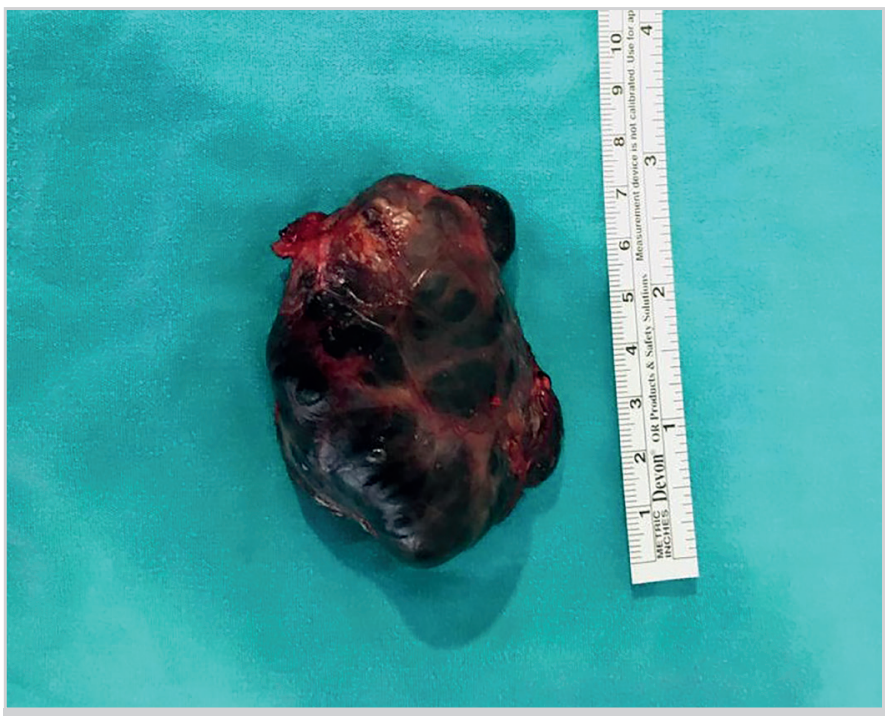

Figure 3. Totally excised cystic mass

with multiloculated lumen covered in ciliated and focal stratified squamous epithelium in larger areas. Psammoma bodies were observed on the cyst wall in some areas (Figure $4 \mathrm{a}, \mathrm{b}$ ). In another focal plane, fine papillary structures were observed in the cystic cavity that was covered in ciliated epithelium (Figure 4c). In another area, on the BCC wall with fibrotic and lymphoid aggregates, coarse papillary structures composed of vesicular nucleus follicle epithelium cells containing colloid consistent with papillary carcinoma were observed (Figure 4d). Papillary carcinoma cells showed positive in immunohistochemical staining with thyroglobulin (TG) (Figure 4e). Squamous epithelium cells observed in the cyst lumen stained positive with $\mathrm{p} 40$, but negative with TG (Figure 4f). Thyroid function tests of the patient were normal. In ultrasonography (USG) of the thyroid and the neck, a nodular lesion of 10x8 mm was observed in the right lobe that was well-circumscribed with a slightly lobulated contour, contained solid cystic components as well as hypervascularization and spotty calcifications. Solid nodules containing microcalcifications were observed in the left lobe. Additionally, lymph nodes up to $16 \times 10 \mathrm{~mm}$ in size that showed cystic necrotic characteristics were observed in the left cervical chain. No lymph nodes with pathological character or size were identified in the right cervical region. Total thyroidectomy and left functional neck dissection was performed under general anesthesia. In pathological examination two focal PTCs of $1.5 \mathrm{~cm}$ and $1 \mathrm{~cm}$ were identified in the left lobe of the thyroid gland, and the larger showed invasion into the thyroid gland capsule. One PTC focus of $1.2 \mathrm{~cm}$ was identified in the right lobe. In addition to the metastasis into the $\mathrm{BCC}$, five metastatic lymph nodes were observed in the neck dissection material. FNAB samples that were reported to be of benign cytology were retrospectively examined for TG, but no staining was identified. In consultation with the Endocrinology Department the patient was prescribed levothyroxine $100 \mathrm{mcg} /$ day in the postoperative period and referred to radioactive iodine therapy. Consent was obtained from the patient for using his medical images.

\section{Discussion}

Neck masses may occur in association with congenital, inflammatory, benign or malignant conditions. Congenital conditions may present in the first decade of life, while malignant conditions in adults and in advanced ages.

Branchial cysts are among the most common lateral neck masses. They are mostly seen in the $2^{\text {nd }}$ to $4^{\text {th }}$ decades of life. Because PTC has a tendency for cystic metastasis into the neck, PTC metastasis can be confused with BCC (3). Apart from this, malignant diseases like squamous cell carcinoma and papillary thyroid carcinoma in BCC can be rarely seen. While PTC originating from the ectopic thyroid tissue develops in the branchial cyst, they can also occur as PTC metastases developing in the thyroid gland (4). Further, considering the tendency for cystic metastasis into the neck of squamous cell carcinomas of the Waldeyer's ring, it should be born in mind that many cystic neck masses that are deemed to be benign may, even if rarely, contain malignant tumor metastases (5). Imaging techniques such as USG, CT and magnetic resonance imaging (MRI) are used in neck masses following the anamnesis and the physical examination. While solid cystic structures can be discriminated in USG, their anatomic structures and positions with respect to one another can be identified in detail 

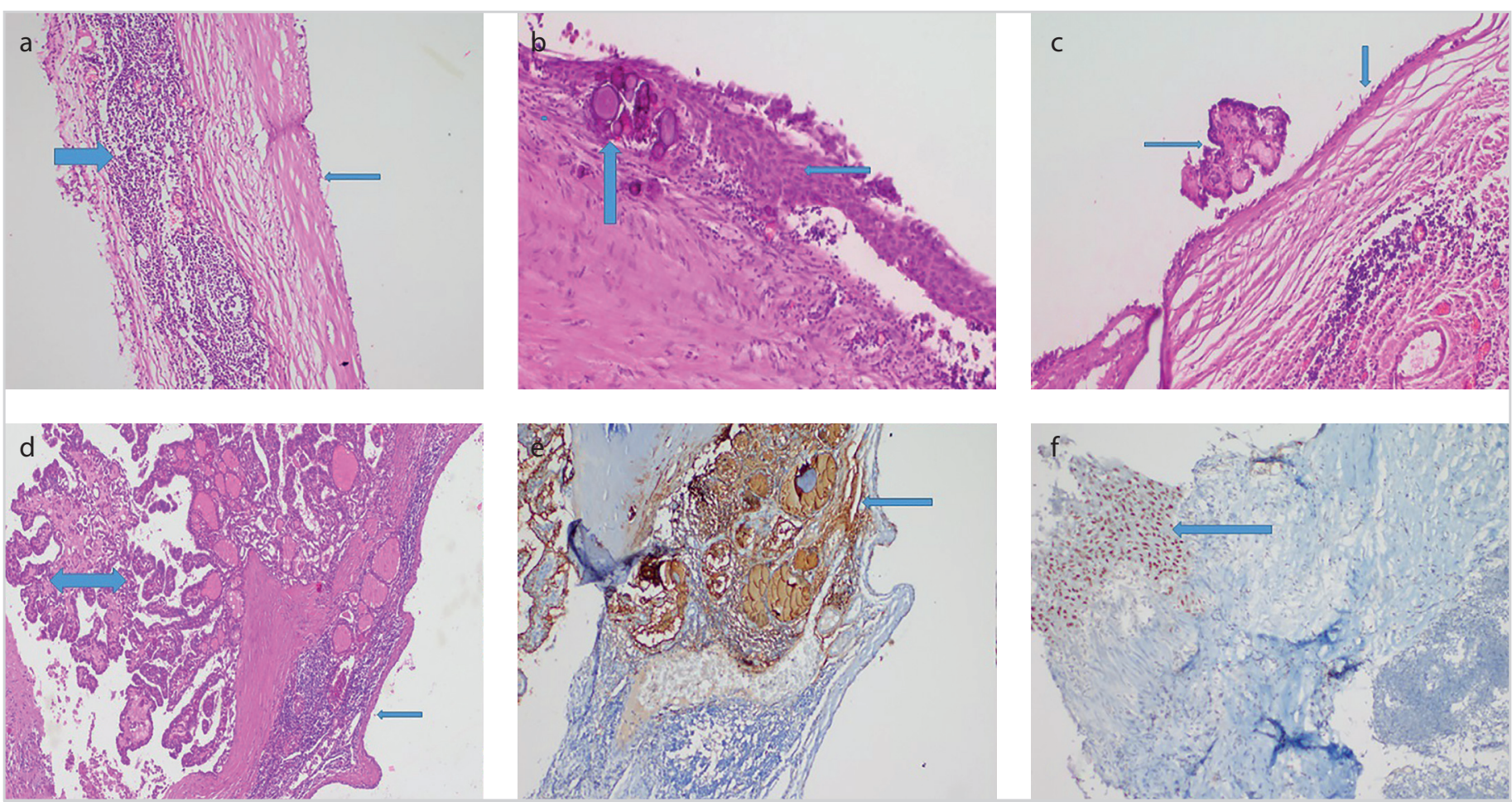

Figures 4. a-f. BCC with a wall surrounded by fibrous tissue containing lymphoid aggregate and covered in ciliated epithelium (H-E, X100) (a). BCC containing psammoma bodies in the cyst wall and squamous epithelium in focal areas (thick arrow: psammoma bodies; thin arrow: squamous epithelium (H-E, X100) (b). Intra-cystic papillary structures on the BCC wall (thick arrow: ciliated epithelium; thin arrow: fine papillary structures) (H\&E, X100) (c). Papillary structures containing colloid and covered with vesicular nucleus papillary carcinoma cells (thick arrow: papillary carcinoma focal; thin arrow: ciliated epithelium) (H\&E, X100) (d). Immunohistochemically positive staining for TG (arrow) in focal papillary carcinoma (TG, X100) (e). Positive staining for p40 (arrow) in covering squamous epithelium of the BCC (P40, X100) (e).

in CT and MRI. After these examinations FNAB is performed for diagnosis, however, malignant cells can be identified with a success rate of around $50 \%$ because of cellular component dilution by cyst fluid in cystic masses (6).

Branchial cleft cysts may contain ectopic thyroid tissues in which PTC can, albeit rarely, develop in this thyroid tissue (7). In such case, no tumors will be found in the thyroidectomy specimen but only in the BCC. In our case, pathologic examination showed both a BCC area consistent PTC metastasis, and an area covered in normal cyst epithelium that was inconsistent with metastasis. Therefore, we considered not a cystic PTC metastasis into the neck but a PTC metastasis into the BCC.

Seven et al. (8) identified PTC in four (11\%) of their $37 \mathrm{pa}^{-}$ tients with lateral neck mass and found their mean age to be 29 . Likewise, Al-Ashaa et al. (9) in their study including five PTC cases with lateral cystic mass, reported to have performed and found positive immunohistochemical TG staining of FNAB in one patient.

Diagnostic accuracy of fine needle aspiration biopsy in cystic masses varies, with a false negative rate of $50 \%$ to $67 \%$ (10). Nevertheless, thyroglobulin levels can be measured in the cystic fluid content obtained with FNAB and metastatic thyroid carcinomas can be identified by these levels. Sometimes thyroglobulin can be identified in FNAB irrigation fluids for cystic lymph nodes, in which case a thyroglobulin level of more than $100 \mathrm{ng} / \mathrm{mL}$ in the
FNAB irrigation fluid will be significant for PTC metastasis (7). In our case, thyroglobulin levels in the FNAB cyst content were not measured. Therefore, the patient was taken to surgery for a second time for thyroidectomy and neck dissection after histopathologic examination revealed PTC metastasis into BCC. No positive staining for TG was identified in the retrospective examination of the FNAB sample that was initially reported as benign. In the light of these results and the available literature $(7,9)$ we can say that in cases which PTC has metastasized into a benign BCC, tumor cells may not be identified in cytology by an FNAB of the mass or by TG staining. Measuring TG levels in the fluid across the cytology material, on the other hand, will give more significant results in terms of a PTC metastasis (7). In lateral cystic neck masses that are initially deemed to be benign BCC, with a FNAB result of benign cystic content, measuring thyroglobulin levels in the FNAB sample, and performing a frozen section during surgery may help to treat the patient in a single procedure and eliminate the need for a second surgery. Performing preoperative thyroid USG in patients with lateral cystic neck mass can further help to preoperatively identify the pathology of the thyroid gland, hence, to perform the procedure in a single session.

\section{Conclusion}

As well as benign and pure cystic masses, neck masses may, albeit rarely, occur as cystic lymphatic metastases of the other organs of the head and neck region. In lateral neck masses that do not suggest malignancy in physical examination, are reported as benign by FNAB results, and deemed to be $\mathrm{BCC}$ in prelim- 
inary diagnosis, the possibility of a rare PTC metastasis should be born in mind. Examining thyroglobulin levels in the FNAB sample in cases of lateral cystic neck masses can help to make this rare diagnosis and to treat the patient in a single procedure. Although such preoperatively performed examinations may allow for the appropriate patient management, diagnosis of thyroid papillary carcinomas that metastasize into the branchial cyst wall, as reported in the literature and as was the case in our patient, is possible only by a histopathologic examination performed after surgery.

Informed Consent: Written informed consent was obtained from the patient who participated in this study.

Peer-review: Externally peer-reviewed.

Author Contributions: Concept - H.G., R.B.A., O.İ; Design - H.G., Y.V., A.D.; Supervision - H.G., O.I., K.G.; Resource - O.I., Y.V., K.G.; Materials - H.G., A.D., Y.V.; Data Collection and/or Processing - O.İ, R.B.A., A.D.; Analysis and/or Interpretation - H.G., Y.V., K.G.; Literature Search - O.İ, A.D., Y.V.; Writing - H.G., O.İ., Y.V.; Critical Reviews - H.G., O.İ., K.G.

Conflict of Interest: The authors have no conflicts of interest to declare.

Financial Disclosure: The authors declared that this study has received no financial support.

\section{References}

1. Flint PW, Haughey BH, Lund VJ, Niparko JK, Robbins KT, Thomas JR, Lesperance MM, editors. Cummings Otolaryngol- ogy, Head and Neck Surgery, 6th edition. Philadelphia: Elsevier Saunders; 2015. p. 1913-15.

2. Tansuker HD, Uslu Coşkun B, Sözen ME, Başak T, Dadaş B. Brankial kleft kisti: Seksen dört yaşında hastada nadir tanı: Olgu sunumu. Turk Arch Otorhinolaryngol 2011; 49: 22-4. [CrossRef]

3. Özergin Coşkun Z, Çelebi Erdivanlı Ö, Güçer H, Özgür A, Demirci M, Dursun E. Cystic nodal metastasis of thyroid papillary carcinoma mimicking branchial cleft cyst: Two case reports. Turk Arch Otorhinolaryngol 2012; 50: 78-80. [CrossRef]

4. Tazegul G, Bozoğlan H, Doğan Ö, Sari R, Altunbaş HA, Balci MK. Cystic lateral neck mass: Thyroid carcinoma metastasis to branchial cleft cyst. J Cancer Res Ther 2018; 14: 1437-38. [CrossRef]

5. Sheahan P, O'leary G, Lee G, Fitzgibbon J. Cystic cervical metastases: Incidence and diagnosis using fine needle aspiration biopsy. Otolaryngol Head Neck Surg 2002; 127: 294-8. [CrossRef]

6. Ozdamar OI, Acar GO, Kafkasli C, Kalcioglu MT, Zenginkinet T, Tamer HG. Papillary thyroid microcarcinoma with a large cystic dilated lymph node metastasis to the neck mimicking a branchial cleft cyst: A potential pitfall. Case Rep Otolaryngol 2015; 2015: 796358. [CrossRef]

7. Park J, Kwon SY, Kim NH, Baik SH, Choi DS. Papillary thyroid carcinoma arising in a branchial cleft cyst. Thyroid 2010; 20: 3479. [CrossRef]

8. Seven H, Gurkan A, Cinar U, Vural C, Turgut S. Incidence of occult thyroid carcinoma metastases in lateral cervical cysts. Am J Otolaryngol 2004; 25: 11-7. [CrossRef]

9. Al-Ashaa Y, Hefny AF, Joshi S, Abu-Zidan FM. Papillary thyroid carcinoma presenting as a lateral neck cyst. Afr Health Sci 2011; 11: 296-300.

10. Chi HS Wang LF, Chiang FY, Kuo WR, Lee KW. Branchial cleft cyst as the initial impression of a metastatic thyroid papillary carcinoma: two case reports. Kaohsiung J Med Sci 2007; 23: 634-8. [CrossRef] 